\title{
Extragenital granuloma inguinale (Donovanosis) diagnosed in the United Kingdom: a clinical, histological, and electron microscopical study
}

\author{
DV SPAGNOLO,${ }^{*}$ PR COBURN,$\dagger J J$ CREAM, $\dagger$ BS AZADIAN $\ddagger$
}

From the Departments of ${ }^{*}$ Histopathology, $\dagger$ Dermatology, and $\ddagger$ Medical Microbiology, Charing Cross Hospital, London W6

SUMMARY An extremely rare case of primary extragenital granuloma inguinale affecting the axillae is reported. Clinical, histological, and electron microscopical features of the disease are described, and the rarity, absence of genital lesions, and consequent difficulty in diagnosis are emphasised.

Granuloma inguinale is an indolent, progressive, ulcerative, and granulomatous disease of low infectivity caused by Calymmatobacterium granulomatis (Donovania granulomatosis).' It occurs widely throughout the tropical and subtropical areas of the world. It usually affects the dermis and subcutaneous tissues of the genital, perineal, and perianal regions.

Local spread to contiguous pelvic organs or anorectal areas is well known ${ }^{12}$ and extragenital lesions have been reported in up to $6 \%$ of cases. ${ }^{2}$ These extragenital sites include the oral cavity, ${ }^{23}$ the lips, ${ }^{4}$ the orbit and orbital bone, ${ }^{5}$ and the scalp, ${ }^{6}$ when spread is thought to be by inoculation from genital or inguinal lesions. Some of these cases, however, have occurred in the absence of anogenital lesions. ${ }^{2-46}$ Haematogenous spread may also occur to bone, ${ }^{7}$ joints, lung, liver, and spleen. ${ }^{8}$ There has been some debate about whether transmission is venereal or non-venereal. ${ }^{\prime 9}$ In some patients with extragenital lesions there are no pelvic lesions nor any history of oral sex, and such patients may have a primary extragenital infection. ${ }^{36}$

\section{Case report}

A 22 year old West Indian girl from Trinidad developed a rash in the right axilla in October 1981. Shortly afterwards a similar lesion appeared in the left axilla, and both lesions began to spread to the adjacent chest wall and upper arms (Fig. 1). She applied topical antifungal agents and had a short course of oral ampicillin without benefit. She did not complain of systemic symptoms. In October 1982 she visited the UK and sought medical attention.

Accepted for publication 2 May 1984
On examination she appeared well and was not feverish. There were raised, scaly, and indurated plaques in both axillae and on the upper arms (more striking on the right), with a doughy feel and an erythematous advancing edge, extending on to the adjacent chest wall. There was no local or distant lymphadenopathy and there were no genital or oral lesions.

\section{INVESTIGATIONS}

Investigations showed a normal chest radiograph; a Mantoux 1/1000 was negative but a Candida skin test showed a normal response at $48 \mathrm{~h}$. Skin scrapings and cultures for fungi were negative. Altogether three skin biopsies were taken before the correct diagnosis was made; histopathological and electron microscopical findings are discussed below. All three biopsies grew Serratia marcescens, but mycobacterial (typical and atypical) and leishmania infections were excluded by appropriate cultures. Serological tests for syphilis were negative and the lymphogranuloma venereum CFT was less than 5 .

\section{MATERIAL AND METHODS}

For light microscopy the skin biopsies were fixed in $10 \%$ buffered formalin, routinely processed, and embedded in paraffin wax. Five micron sections were stained with haematoxylin and eosin, periodic acid Schiff, and Gram, Giemsa, Ziehl-Neelsen, and Warthin-Starry silver stains. Air dried imprint smears were made from the cut surface of the last biopsy specimen, and these were stained with Giemsa and Warthin-Starry stains.

For electron microscopy $1 \mathrm{~mm}^{3}$ fragments of fresh tissue were placed in modified Karnovsky fixative (2\% paraformaldehyde, $2.5 \%$ glutaraldehyde in 


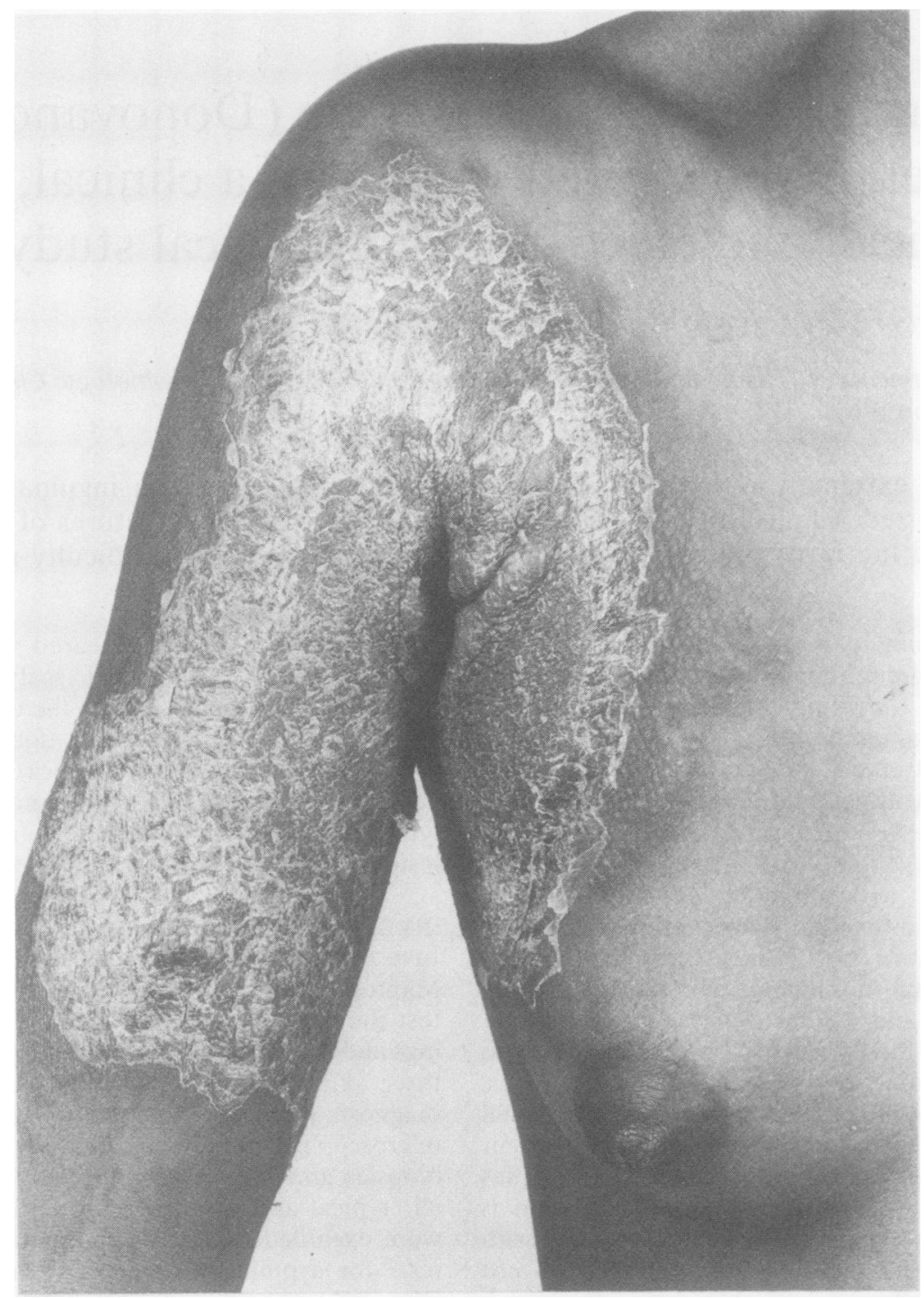

Fig. 1 Axilla and arm lesion. Note advancing erythematous edge.

$0 \cdot 1 \mathrm{M}$ cacodylate buffer, $\mathrm{pH} 7 \cdot 3$ ) for $4 \mathrm{~h}$. After washing in cacodylate-sucrose rinse the tissue was postfixed for $1 \mathrm{~h}$ in $1 \% \mathrm{OsO}_{4}$ in $0.1 \mathrm{M}$ cacodylate buffer, block stained with $2 \%$ aqueous uranyl acetate for $30 \mathrm{~min}$ at room temperature, dehydrated in graded solutions of ethanol, and embedded in Araldite. Thin sections were cut with a diamond knife on a Reichert Ultracut ultramicrotome and examined on a Philips 201 electron microscope.

\section{RESULTS}

Light microscopical findings

All three biopsies showed essentially the same fea- tures. The skin and subcutis contained a heavy, patchy, and confluent inflammatory infiltrate with fibrosis in the intervening areas. The overlying epidermis was hyperplastic but not ulcerated. The most striking feature was focal collections of large, pale, histiocytes measuring up to $40 \mu \mathrm{m}$ in diameter and possessing irregular vesicular nuclei with small nucleoli and voluminous, pale, vacuolated, cytoplasm (Fig. 2). In places, plasma cells and neutrophil polymorphonuclear leucocytes predominated in the infiltrate; the latter were often present in small collections almost forming microabscesses.

Giemsa staining of smears and paraffin sections 


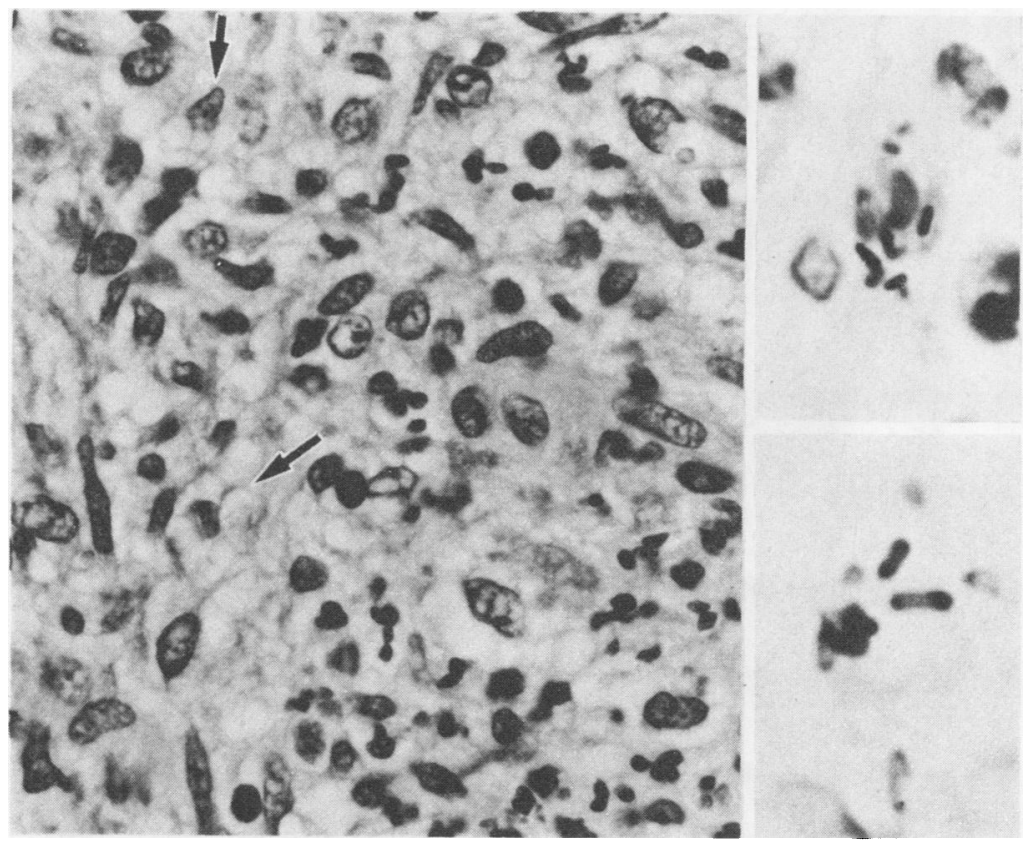

Fig. 2 High power view of dermal inflammatory infitrate including many large histiocytic cells with vesicular nuclei and vacuolated cytoplasm (arrows), and scattered neutrophil polymorphonuclear leucocytes (lower right). Haematoxylin and eosin. Original magnification $\times 600$. Upper inset: Two histiocytes containing several Donovan bodies. Warthin and Starry. Original magnification $\times 1500$. Lower inset: Two Donovan bodies within histiocyte cytoplasm. Note the characteristic "closed safety pin" appearance of the lower organism due to bipolar accentuation of the silver stain. Warthin and Starry. Original magnification $\times 3000$.

showed varying numbers of bacilliform organisms in the cytoplasm of the histiocytes and occasionally within neutrophil polymorphonuclear leucocytes. Warthin-Starry silver staining showed the organisms to better advantage; these were seen as rods of varying lengths, often with distinctive bipolar accentuation of the silver staining (Fig. 2 insets) producing the so called "closed safety pin" appearance typical of Donovan bodies ( $C$ granulomatis), not to be confused with Leishman-Donovan bodies. The organisms were Gram and periodic acid Schiff negative, measured from 1 to $2 \mu \mathrm{m}$ in length, and numbered from one to several in any one cell.

\section{Ultrastructural findings}

Mononuclear phagocytes were the predominant cells present, some containing bacilliform organisms consistent with $C$ granulomatis. Less frequently, organisms were found in neutrophil polymorphonuclear leucocytes, and rarely were free in the surrounding stroma. Cells containing the organisms were relatively few in all of the tissue sampled, and most of the organisms found were poorly preserved and degenerate in appearance.

The organisms were present individually within single phagocytic vacuoles. An electronlucent zone, probably capsular material, separated the organisms from the trilaminar limiting membrane of the phagosomes (Fig. 3a). The bacilli varied from round to elliptical, depending on the plane of sectioning, and ranged from 1.0 to $2.0 \mu \mathrm{m}$ in length. They possessed a sinuous cell wall with an outer tripartite membrane separated by a thin, relatively lucent zone from the trilaminar cell membrane. One organism, apparently dividing, showed a central constriction with invagination of both cell wall and cell membrane (Figs. 3b and 3c). The bacilli had an amorphous central nucleoplasm, peripheral cytoplasm containing aggregates of ribosomes, and were non-flagellate.

\section{TREATMENT AND PROGRESS}

When the diagnosis was finally established after the third biopsy, the patient was treated with oxytet- 


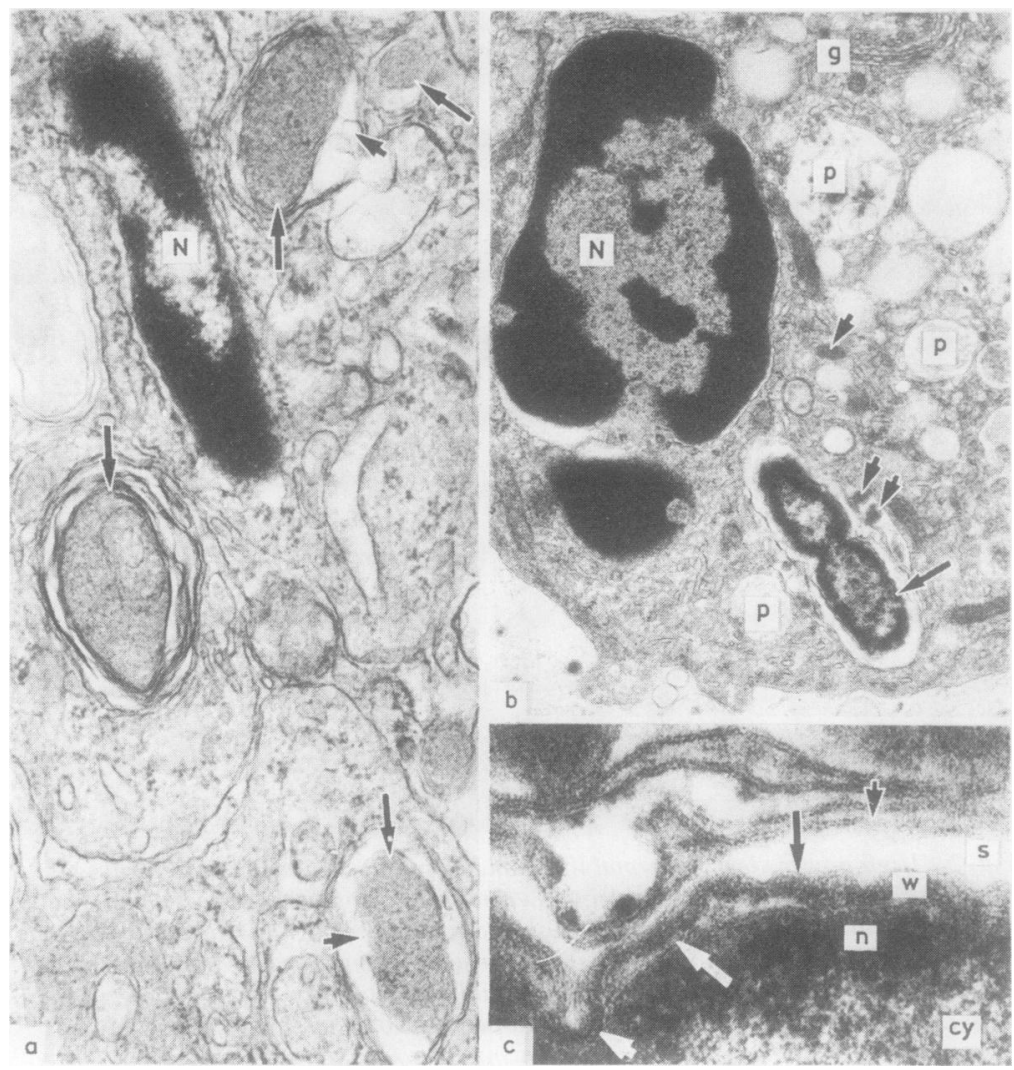

Fig. 3 (a) Four Donovan bodies are seen in this electron micrograph (arrows) within membrane bound phagolysosomal vacuoles of histiocytes. Note the clear spaces (arrow heads), probably capsular material, containing some membranous strands separating the organisms from the lysosomal membrane. $N=$ nucleus. Original magnification $\times 39000$. (b) Electron micrograph showing a dividing Donovan body with a central constriction within a phagolysosomal vacuole (arrow) of a polymorph. Arrow heads indicate small primary lysosomes. $N=$ nucleus, $g=$ golgi, $p=$ phagolysosomes. Original magnification $\times 19845$. (c) High power detail of the dividing Donovan body. A clear space (S) separates the organism from the phagolysosomal membrane (arrow head). The sinuous cell wall of the organism (w) has an outer trilaminar membrane (arrow) and is separated from the cell membrane (white arrow) by a thin lucent zone. Note the invagination of both cell wall and membrane at the point of division (white arrow head). cy = cytoplasm of Donovan body; $n=$ nucleoplasm. Original magnification $\times 166450$.

racycline $500 \mathrm{mg}$ four times daily for 10 days, but the lesions showed no evidence of regression. Cotrimoxazole tablets $480 \mathrm{mg}$ twice daily were then started and the lesions began to regress within $48 \mathrm{~h}$. Co-trimoxazole was continued for 14 days and there was complete healing of the lesions, leaving only postinflammatory hyperpigmentation with no scarring.

\section{Discussion}

When this patient presented, several granulomatous conditions including tuberculosis, late syphilis, lymphogranuloma venereum, and dermal leishmaniasis were considered on clinical grounds and ruled out by the appropriate investigations. Although the patient and histological sections were reviewed in several dermatology and pathology departments, the diagnosis of granuloma inguinale was not initially considered even though the histological picture, dominated by large histiocytes possessing cytoplasmic vacuoles, should, in retrospect, have suggested the possibility. ${ }^{1011}$ The organism was overlooked in the 
first two biopsies.

$C$ granulomatis is seen to best advantage using silver stains such as the Warthin and Starry technique," which produces the classic "closed safety pin" appearances. ${ }^{12}$ The presence in an inflammatory exudate of the characteristic histiocytes, even in an extragenital location, should alert the pathologist to the possibility of granuloma inguinale. Use of a silver stain to identify the organisms can avoid the delay in diagnosis that occurred in this case.

Other infections may produce a similar histological picture dominated by parasitised histiocytes and need to be distinguished from granuloma inguinale. In rhinoscleroma there is nasal involvement, the histiocytic cells (Mikulicz cells) are much larger ( 100 to $200 \mu \mathrm{m})$, and plasma cells are numerous and typically contain many Russell bodies. The causative organism is a Gram negative bacillus with a periodic acid Schiff positive capsule and measures from 2 to 3 $\mu \mathrm{m}$ in length. ${ }^{13}$ The organisms of leishmaniasis are non-encapsulated, measure 2 to $4 \mu \mathrm{m}$ in length, and have a distinct nucleus and paranucleus. ${ }^{14}$ Histoplasma capsulatum appear as rounded spores surrounded by a clear space, measure $2-4 \mu \mathrm{m}$ in diameter, and have a thick periodic acid Schiff positive capsule. ${ }^{15}$

The ultrastructural features of this case are similar to those of other reported cases. ${ }^{16}$ The structure of the bacterial cell wall and membrane and "pinching in" of these structures during division are in keeping with the features described for Gram negative organisms. ${ }^{17}$

Culture of all three biopsy specimens yielded only $S$ marcescens. It was resistant to a variety of antibiotics including tetracycline and co-trimoxazole and was considered to be an insignificant bacterial superinfection. Culture of $C$ granulomatis, in chick embryo yolk sac, is possible but not practical for diagnosis. Serological tests are unreliable.

Tetracycline, chloramphenicol, gentamicin, and ampicillin have all been successful in the treatment of granuloma inguinale.' Our patient's infection appeared to be resistant to both tetracycline and ampicillin, though we are unsure whether the latter was given in adequate dosage. Resistance to both these drugs has been described. ${ }^{18}$ Tetracycline has been considered by some to be the drug of first choice, though in a recent study ${ }^{14}$ co-trimoxazole was suggested as the preferred drug, and it proved effective in our patient.

We would like to emphasise the considerable difficulties that were encountered in the diagnosis of this case largely because of its rarity in the UK, the absence of genital lesions, and our failure to consider it in the clinical differential diagnosis. We also emphasise that granuloma inguinale should be con- sidered in the differential diagnosis of chronic granulomatous and non-granulomatous inflammatory conditions in both genital and non-genital sites, particularly in patients from tropical or subtropical countries, and that appropriate silver stains on smears or tissue will avoid delay in diagnosis.

We thank Mr M Aguirreburualde for technical assistance, Mr R Barnett for the photomicrography, $\mathrm{Mr}$ $\mathrm{T}$ Bull for the electron micrographs, and Mrs B Longley for typing the manuscript.

\section{References}

' Kuberski T. Granuloma Inguinale (Donovanosis). Sex Transm Dis 1980;7:29-36.

2 Rajam RV, Rangiah PN. Donovanosis (Granuloma inguinale, Granuloma venereum). WHO Monogr Ser 1954;24:1-72.

${ }^{3}$ Subba Rao M, Kameswari VR, Ramulu C, Reddy CRRM. Oral lesions of granuloma inguinale. J Oral Surg 1976;34:1112-4.

${ }^{4}$ Hanna CB, Pratt-Thomas HR. Extragenital granuloma venereum. Report of six cases of lip, oral and cutaneous involvement with review of literature. South Med J 1948;41:776-82.

${ }^{5}$ Endicott JN, Kirkconnell WS, Beam D. Granuloma inguinale of the orbit with bony involvement. Arch Otolaryngol 1972;96:457-9.

- Sehgal VN, Sharma NL, Bhargava NC, Nayar M, Chandra M. Primary extragenital disseminated cutaneous donovanosis. $\mathrm{Br}$ J Dermatol 1979;101:353-6.

' Kirkpatrick DJ. Donovanosis (Granuloma Inguinale): A rare cause of osteolytic bone lesions. Clin Radiol 1970;21:101-5.

${ }^{8}$ Rajan RV, Rangiah PN, Anguli VC. Systemic donovaniasis. Br J Vener Dis 1954;30:73-80.

${ }^{9}$ Goldberg J. Studies on Granuloma Inguinale VII. Some epidemiological considerations of the disease. Br J Vener Dis 1964;40:140-5.

${ }^{10}$ Pund ER, Greenblatt RB. Specific histology of granuloma inguinale. Arch Pathol (Chic) 1937; 23:224-9.

" Dooley JR, Binford CH. Granuloma inguinale. In: Binford CH, Connor DR, eds. Pathology of tropical and extraordinary diseases. Vol 1. Washington DC: Armed Forces Institute of Pathology, 1976:194-6.

12 Torpin R, Greenblatt RB, Pund ER. Granuloma inguinale (Venereum) in female. Am J Surg 1939;44:551-6.

${ }^{13}$ Hyams VJ. Rhinoscleroma. In: Binford $\mathrm{CH}$, Connor DR, eds. Pathology of tropical and extraordinary diseases. Vol I. Washington DC: Armed Forces Institute of Pathology, 1976:187-9.

14 Lever WF, Schaumberg-Lever G. Histopathology of the skin. 5th ed. Philadelphia, Toronto: JB Lippincott Co, 1975:333.

is Lever WF, Schaumberg-Lever G. Histopathology of the skin. 5th ed. Philadelphia, Toronto: JB Lippincott Co, 1975:323.

${ }^{16}$ Kuberski T, Papadimitriou JM, Phillips P. Ultrastructure of Calymmatobacterium granulomatis in lesions of granuloma inguinale. J Infect Dis 1980; 142:744-9.

"Costerton JW. The role of electron microscopy in the elucidation of bacterial structure and function. Ann Rev Microbiol 1979;33:459-79.

18 Thew MA, Swift JT, Heaton CL. Ampicillin in the treatment of Granuloma Inguinale. JAMA 1969;210:866-7.

${ }^{19} \mathrm{Lal}$ S, Garg BR. Further evidence of the efficacy of cotrimoxazole in Granuloma venereum. Br J Vener Dis 1980;56:412-3.

Request for reprints to: Dr JJ Cream, Department of Dermatology, Charing Cross Hospital, Fulham Palace Road, London W6 8RF, England. 